\title{
Assessing the Effects of Practiced Irrigation Methods on Irrigation Water Demand and Allocation among Farmers in Kontsa Irrigation Project, Ethiopia
}

Tesfaye Negasa ( $\square$ yoom2020@gmail.com )

Assosa University

Genemo Barso

Assosa University

Alemu Weyessa

Assosa University

\section{Research Article}

Keywords: Assessment, Demand, Kontsa, Water allocation, WEAP

Posted Date: January 4th, 2022

DOI: https://doi.org/10.21203/rs.3.rs-1227059/v1

License: (c) (1) This work is licensed under a Creative Commons Attribution 4.0 International License.

Read Full License 


\title{
Assessing the Effects of Practiced Irrigation Methods on Irrigation Water Demand and
}

\section{Allocation among Farmers in Kontsa Irrigation Project, Ethiopia}

\author{
Tesfaye Negasa ${ }^{1}$, Genemo Barso ${ }^{2}$, Alemu Weyessa ${ }^{3}$ \\ ${ }^{1-3}$ Department of Water Resources and Irrigation Engineering, College of Engineering, Assosa \\ University, Assosa, 18, Ethiopia
}

\begin{abstract}
Increasing of demand for water, allocation of limited water resources, climatic variability, degradation of water in the environment and developing of policies for sustainable water use are issues of increasing concern in the Kontsa irrigation project. This study aimed at assessing the effects of selected irrigation methods on water demand and allocation among farmers in Kontsa irrigation project. The study employed both primary and secondary data. The primary data were collected by interviewing 80 farmers, key informant interviews and observation of the project area while secondary data were collected from different agencies of Ethiopia. For this study Water Evaluation and Planning (WEAP) model was used to model the current situation of irrigation water demand and also to create scenario for future irrigation water demand. The model was set up for a current account year in 2015 and last year of scenarios in 2040 based on the available data. Then the irrigation water demand of the project area was modeled while giving consideration for existing and planned developments in the area. The result from the current situation of irrigation water demand indicated that the demand was satisfied fully and the unmet demand under the base year (2015) was zero. Additionally, irrigation expansion scenario was created and the result of this scenario indicates the increment of irrigation water demand as compared to the base year and the reference scenario. The study also revealed that furrow irrigation and plastic buckets were the main irrigation techniques employed by farmers in the study area.
\end{abstract}

Keywords: Assessment, Demand, Kontsa, Water allocation, WEAP

\section{Introduction}

Among the different uses of water, agricultural water use has been considered to be critical factor in assuring food security and protection against adverse drought conditions. It also important in 
sustaining incomes of farmers by providing greater opportunity for crop diversification (Hussain $e t$ al., 2011). However, water availability for irrigation in Africa is already limited, and this is set to worsen in the near future (WWAP, 2012). Hence forth, several countries in Sub Saharan Africa region are already facing absolute water scarcity, and water is distributed inequitably among farmers in the upstream and downstream reaches of rivers in many regions (Hamdy, 2005). Moreover, inequitable water allocation has also been identified as one of the causes of poor performance by some farmers in these countries. The increasing water scarcity has complicated irrigation water allocation and this subsequently has led to more people questioning its value (Hope et al., 2008).

Furthermore, in Ethiopia, irrigation agriculture is commonly practiced by smallholder farmers. Farmers utilize most of the available water but with very low efficiencies leading to water stress. Most of the irrigation water is used for growing a variety of crops such as coffee, banana, maize, flowers and vegetables. Nonetheless, despite the big amounts of fresh water available, farmers are still faced with shortages of water in Kontsa command area in the Ma'o-Komo district. In Kontsa irrigation area, the demand for irrigation water has increased enormously causing serious water allocation challenges. Thus, the area has often experienced a problem of inequitable distribution of irrigation water among farmers (MoFED, 2002). These challenges are escalated by rapid population growth, economic growth, other water users' sectors and irrigation management technologies adopted by farmers. Moreover, the river is experiencing water over abstraction as a result of increased irrigation activities. This has placed the river under water stress and in the recently years there has been a decline in the river flow (MoWRD, 2008).

Hence, the purpose of this study was to assess the effects of practiced irrigation methods on water demand and water allocation among farmers in Kontsa irrigation area of the Ma'o-Komo district for holistically and sustainable water management. This study used Water Evaluation and Planning (WEAP) model for creating and analyzing scenarios of water demand development in the area. The 
model is used to assess water demand and model the impacts of different water allocation scenarios aimed to meet irrigation water demand in the project area.

\section{Materials and Methods}

\subsection{Description of the Study Area}

Kontsa irrigation project is located in Mao-Komo Special district, Benishangul Gumuz regional State, Ethiopia, between UTM of 656572E and 1066191N. The study area has an average annual rainfall of $900 \mathrm{~mm}-1450 \mathrm{~mm}$ per year. The monthly average temperature range is $20^{\circ} \mathrm{C}$ to $30^{\circ} \mathrm{C}$. The elevation of the study area ranges between 950 meter and 1960 meter above sea level.

\subsection{Materials Used}

The materials and software used in this study were:

i) ArcGIS: for delineation of the study area, mapping and geo-referencing of the collected information and to refine the area boundaries,

ii) WEAP: for the estimation of water demands and creation of scenarios,

iii) CROPWAT: to determine crop water requirement of the crops,

iv) PEST: for calibration and validation, v) MS-Excel: for data processing

vi) GPS: for mapping of farmers activities nearby the river and irrigation techniques conducted along the river

\subsection{Model Selection Criteria}

Water Evaluation and Planning (WEAP) model was selected for this study because of its adaptability to whatever available data to describe a water resources system, its ability to use daily, weekly, monthly, or annual time-steps to characterize the system's water supplies and demands, its flexibility to be applied across a range of spatial and temporal scales, its usability throughout the world to analyze a diverse set of water management issues for small communities and large managed watersheds alike, its operation in an optimization of water allocation based on priorities set for each demand site (SEI, 2012). 


\subsection{Demand Calculations in WEAP}

A demand site's (DS) demand for water is calculated as the sum of the demands for all the demand site's bottom-level branches $(\mathrm{Br})$. A bottom-level branch is one that has no branches below it. Annual water demand was then calculated as follows:

Annual Demand DS = (Total Activity Level Br x Water Use Rate Br) $B r$

The total activity level for a bottom-level branch is the product of the activity levels in all branches from the bottom branch back up to the demand site branch (where $\mathrm{Br}$ is the bottom-level branch, $\mathrm{Br}^{\prime}$ is the parent of $\mathrm{Br}, \mathrm{Br}$ " is the grandparent of $\mathrm{Br}$, etc.). The total activity level was given as:

Total Activity Level $\mathrm{Br}=($ Activity Level Br x Activity Level Br' x Activity Level Br" x.....)

The activity levels for each branch and the water use rates for all the bottom-level branches are inputs into the model. Monthly demands were calculated based on each month's fraction specified as data under demandlmonthly variation of the adjusted annual demand as follows:

Monthly Demand DS,m = Monthly Variation Fraction DS,m * Adjusted Annual Demand DS (SEI, 2012).

\subsection{Methods of Data Collection and Collected Data}

To acquire the required information needed to meet the objectives of the study, both primary and secondary data collection techniques were employed for this study. Primary data collection technique such as field observation of the study area, questionnaires and collection of UTM locations by using GPS were undertaken. Secondary data collection technique such as document review of previous studies and other related books; journals, articles, newspapers and magazines and from internet were undertaken. For this study data such as hydrological data (stream flow data), meteorological data (rainfall, temperature, relative humidity, sunshine hour, wind speed), DEM data, irrigation data (agricultural land area, agricultural monthly variation demands, water requirements per hectare of the crops) were required. This all data was collected from different places or agencies and is shown in the table 1. 
Table 1 Data type and their respective sources

\begin{tabular}{ll}
\hline Data & Source \\
\hline Hydrological Data & Ministry of Water, Irrigation and Electricity of Ethiopia \\
Meteorological Data & National Metrological Service Agency of Ethiopia \\
Spatial Data & Ministry of Water, Irrigation and Electricity of Ethiopia \\
Irrigation Water Demand Data & Ministry of Water, Irrigation and Electricity of Ethiopia, \\
& Agriculture and Rural Development Bureau \\
Data for Scenario Creation & MWIE of Ethiopia, Agriculture and Rural Development \\
& Bureau of the Benishangul Gumuz Regional State \\
Data for Calculation of Crop & NMSA of Ethiopia, design document, FAO \\
Water Requirement (CWR) &
\end{tabular}

\subsection{Methods of Data Analysis}

After the data was collected, an analysis of all the collected data was made. The acquired data were checked for any outliers and missing values by using the following methods.

- Analysis of Descriptive Statistic (Microsoft excel)

- $\quad$ Filling missed stream flow data (Interpolation method) (SEI, 2015)

- Water Demand Data Analysis (disaggregating into sub sectors) (SEI, 2011)

\subsection{Modeling Process for Irrigation Water Demand}

To model the water demand of agriculture by using WEAP model the following steps/process were followed.

- Creation of geographic representation of the area

- Setting of general parameters

- Entering elements into the schematics

- Entering of data for demand sites/nodes 
- Connecting demand with supply

- Creating return flow links, running of the model and getting the results

\subsection{Modeling Process for Scenario Creation}

In WEAP, the typical scenario modeling effort consists of the following steps: -

\section{a) Choosing current account year}

The current account (base year) is the year for which good demand data are available and from which future forecasts could be made. It is also the year with most current water use information is reliable and complete data are available and acts as the start year for period of analysis(SEI, 1999). Accordingly, the year 2015 was set as current accounts year and the year 2040 was set as the last year of scenarios for this study.

\section{b) Establishing of the reference scenario and creating of what-if scenario}

Scenarios are alternative sets of assumptions such as different operating policies, costs, and factors that affect demand such as demand management strategies, alternative supply sources and hydrologic assumptions, with changes in these data able to grow or decline at varying rates over the planning horizon of the study (Yates et al., 2005). Accordingly, the created scenarios in this study depends on the assumptions that, what will happen in the project area on the future trends of irrigation water demand if the proposed master plan will be implemented. The following scenarios were developed based on the current situation and the plan prepared by the Agriculture and Rural Development Bureau of the Benishangul Gumuz Regional State.

Reference Scenario: Reference scenario (2015-2040) represents the changes that are likely to occur in the future without intervention of new policy measures.

\section{Irrigation Expansion Scenario (2021-2040)}

According to the plan the implementation of the Kontsa irrigation project (223ha) was divided into two phases, the implementation of the first phase was assumed to be completed until 2020 which includes an implementation of 173ha. The remaining area (50ha) will be planned to be 
implemented in the year between (2021-2040). Thus, under this scenario will bring answer to what happen to the future irrigation water demand of the area if the Kontsa irrigation project area is increased from 173ha to 223ha.

\subsection{Model Calibration, Validation and Performance Evaluation}

The calibration procedure was undertaken using the WEAP model. Validation was done by applying the calibrated model using a different data set out of the range of calibration without changing the parameter values. Observed and simulated stream flow values were compared as in the calibration procedure. If the resultant fit is acceptable then the model 's prediction as valid. Finally, the model performance was evaluated for both calibration and validation using efficiency criteria. For the performance evaluation criteria's the Nash-Sutcliffe efficiency (NSE) (Reuben, 2007) and Coefficient of determination $\left(\mathrm{R}^{2}\right)$ (Moriasi et al., 2007) were commonly used by different authors and also selected for this study.

\section{Results and Discussion}

\subsection{Results of Model Calibration and Validation}

WEAP model was calibrated with discharge data by comparing observed and simulated discharge.

The stream flow comparison has been done between the observed and simulated discharge values during calibration and validation. After a number of optimizations trial the observed and simulated flow shows a good agreement as shown in the Figures 1 and 2.

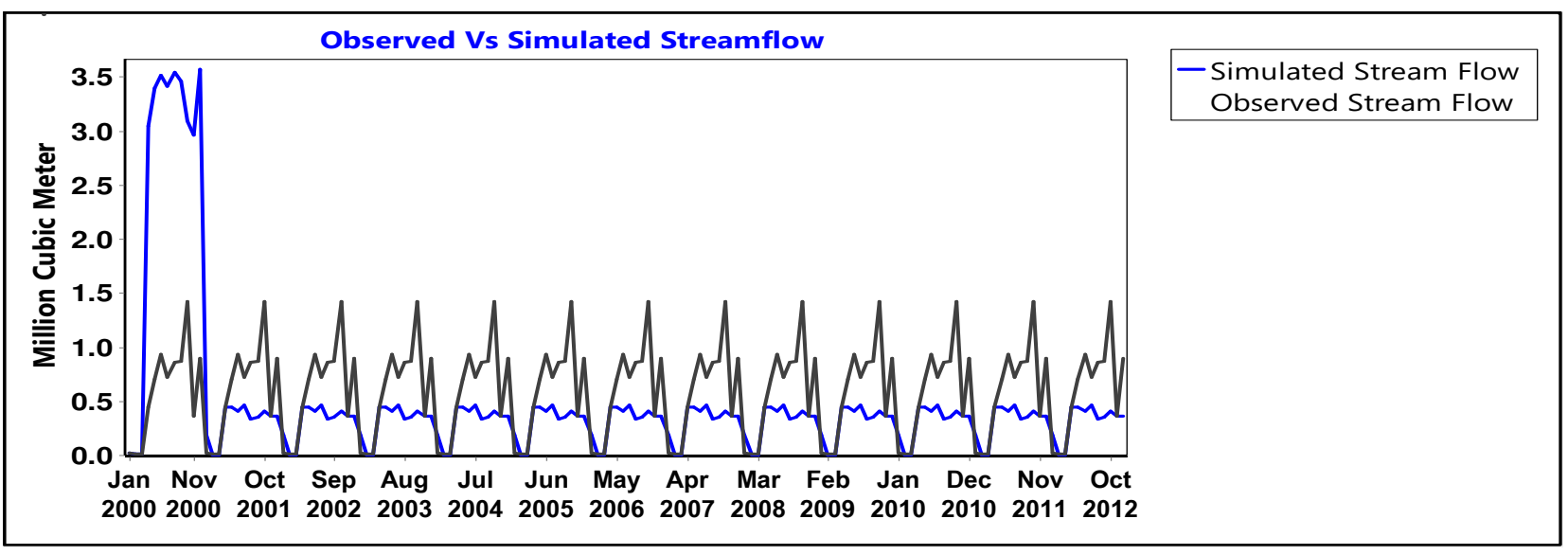

Fig.1 Calibration result of monthly observed and simulated flows 


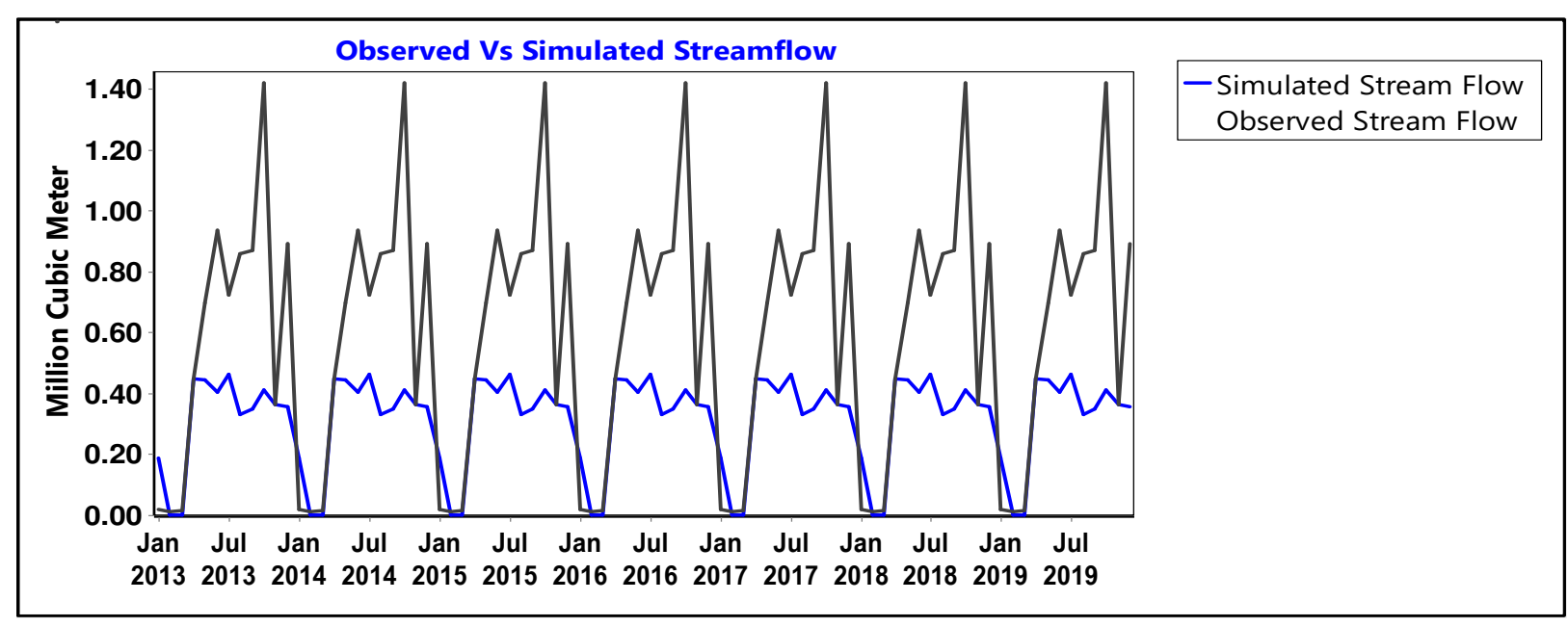

Fig. 2 Validation result of monthly observed and simulated flows

Finally, the results of the model performance evaluation for both calibration and validation using $\mathrm{R}^{2}$ and ENS were shown in the table 2.

Table 2 Observed and simulated flow during calibration and validation

\begin{tabular}{lll}
\hline Evaluation Criteria & $\mathrm{R}^{2}$ & ENS \\
\hline Calibration & 0.9809 & 0.62 \\
Validation & 0.9785 & 0.67 \\
\hline
\end{tabular}

\subsection{Water Availability for the Project Area}

The result of the total average monthly river flow of the Kontsa river from which the crops get their water demand is shown in the Figure 3.

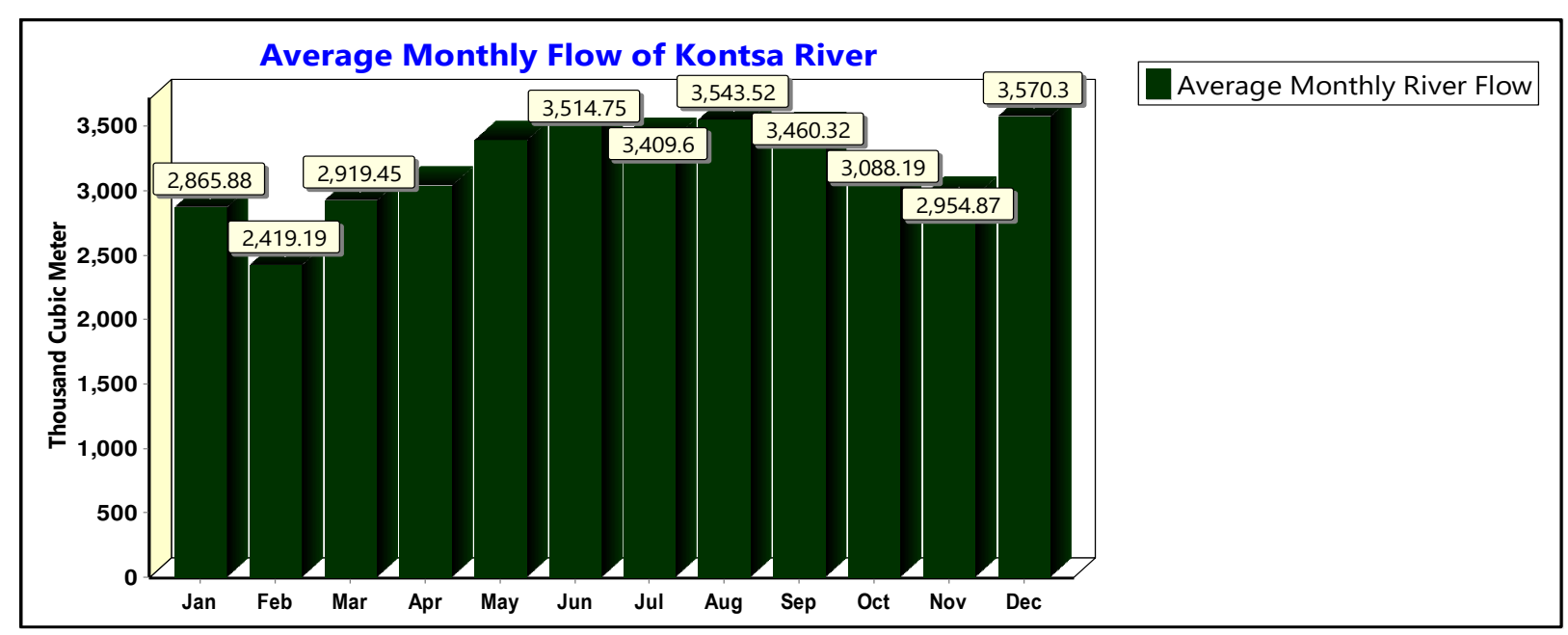

Fig. 3 Average monthly river flow of the Kontsa River 
As portrayed in the Figure 3 the Kontsa River has the total mean monthly stream flow of 38.172 million cubic meter (MCM). This indicates that, the project area has a total surface water potential of 38.172 million cubic meter (MCM) in the base year.

\subsection{Irrigation Water Demand of Kontsa Irrigation Project for the Base Year}

Current situation of irrigation water demand for the base year (2015) of the demand site was modeled before any scenario was developed in order to know the situation of this water demand in the base year (2015) in the area. Accordingly, the result of the situation of irrigation water demand in the base year is shown in the Table 3 .

Table 3 Monthly irrigation water demand in the base year

\begin{tabular}{lc}
\hline Months & Irrigation Water Demand (Thousands $\mathrm{M}^{3}$ ) \\
\hline January & 5.83331434 \\
February & 3.37003308 \\
March & 0.95998219 \\
April & 0 \\
May & 0 \\
June & 0 \\
July & 0 \\
August & 0 \\
September & 0.07525673 \\
October & 2.35865605 \\
November & 5.80761692 \\
December & 18.40485931 \\
Sum &
\end{tabular}

As can be seen in the Table 3 the total irrigation water demand of the project area has been estimated to be 18.40485931 thousands meter cubic for the base year. Also as shown in the Table 3 
regarding to the temporal variation of water demand for the base year, months January, February, November and December requires high water demand. This is because during these months water requirements of the crops were increased. On the other hand, for the months April, May, June, July, August and September irrigation water demand is not required due to the reason that during these months high rainfall was observed.

\subsection{Unmet Irrigation Water Demand in the Base Year}

Unmet demand is the supply requirement that is not met the demand. In this case the unmet irrigation water demand of the demand site for the base period is shown in the Figure 4.

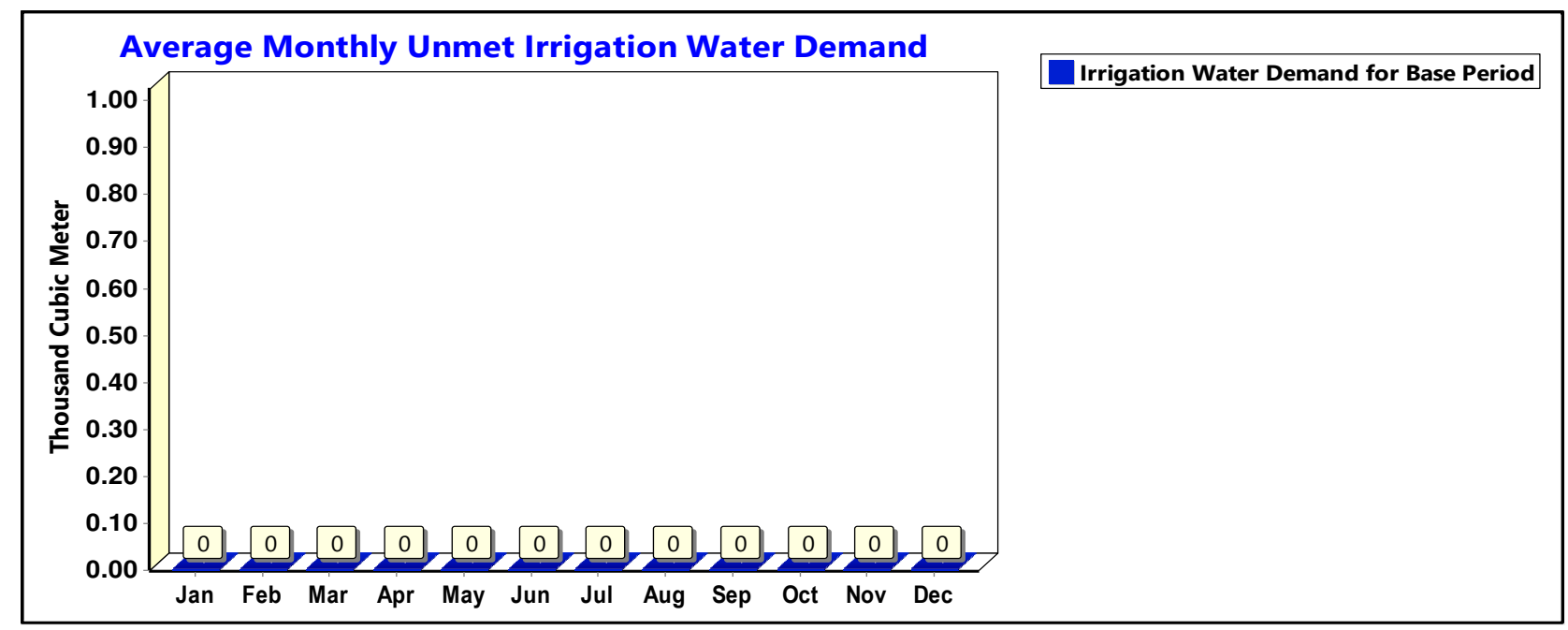

Fig. 4 Monthly unmet irrigation water demand in the base year

The unmet demand result shows that the irrigation water demand is fully met for all months in the base year. This implies that the existence of $100 \%$ supply coverage for the demand site in the base year.

\subsection{Comparison of Water Demand and Supply in the Kontsa Irrigation for the Base Year}

The result of the average monthly water supply and average monthly irrigation demand in the Kontsa irrigation project in the base year are shown in Table 4 to compare the available supply with the requirement.

Table 4 Comparison of available supply with their requirements in the base year

\begin{tabular}{lcc}
\hline Months & Water Availability $\left(\right.$ Thousands $\left.\mathrm{M}^{3}\right)$ & Irrigation Water Demand (Thousands $\mathrm{M}^{3}$ ) \\
\hline January & 2865.88 & 5.83331434 \\
February & 2419.19 & 3.37003308 \\
March & 2919.45 & 0.95998219 \\
April & 3037.82 & 0 \\
May & 3388.17 & 0 \\
June & 3514.75 & 0
\end{tabular}




$\begin{array}{lcc}\text { July } & 3409.6 & 0 \\ \text { August } & 3543.52 & 0 \\ \text { September } & 3460.32 & 0 \\ \text { October } & 3088.19 & 0.07525673 \\ \text { November } & 2954.87 & 2.35865605 \\ \text { December } & 3570.3 & 5.80761692 \\ \text { Sum } & 38172.06 & 18.40485931\end{array}$

As shown in the Table 4 the total irrigation water demand in the base year at the Kontsa irrigation project is estimated to be $0.0184 \mathrm{MCM}$ per year and the total available water is $38.172 \mathrm{MCM}$. This means, from the total water available in the study are which is $38.172 \mathrm{MCM}$ only $0.0482 \%$ has been withdrawal in the base year. This indicates that when the available water supply is compared to the water requirements in the Kontsa irrigation project for the base year, available supply is much greater than the demanded water.

\subsection{Adopted Irrigation Methods for the Kontsa Irrigation Project}

The study investigated two main irrigation techniques employed by farmers namely, furrow and buckets irrigation techniques. Accordingly, the results of the irrigation method used by farmers are shown in the figure 5.

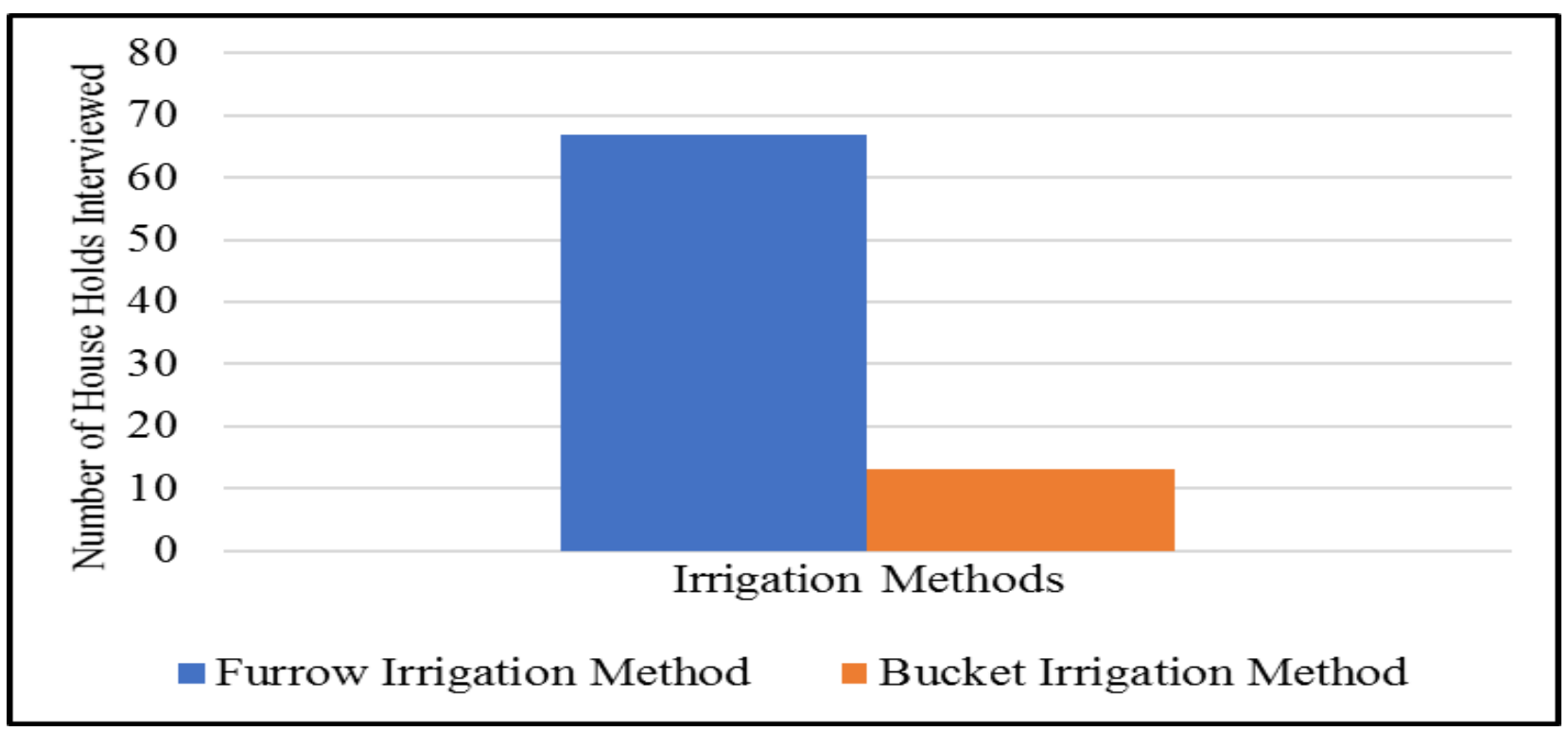

Fig. 5 Methods of Irrigation Employed in the Irrigation Project

According to the results obtained during the field survey, no farmer was reported to use both methods. Nonetheless, furrow irrigation was the dominant in the Kontsa Irrigation Project. The study revealed that $83.75 \%$ of respondents interviewed indicated furrows as the means of irrigation technology to irrigate their crops and the remaining $16.25 \%$ of the respondents interviewed use buckets as the means of irrigation technology to irrigate their crops. Additionally, during the field 
observation the researcher observed that, the house holds which used the bucket technology was those who are at the downstream of the command area. The reason why they prefer to use the bucket method was due to the lack of enough water which passes through the furrows of the upstream users.

\subsection{The Effects of Practiced Irrigation Method on Water Demand}

The study found that furrows are constructed of unlined earth and normally lose a lot of water. Moreover, the system is less organized, technically inferior and water inefficient. Additionally, there were also several leakages points from unlined furrow through the earthen materials. The study found that $16.25 \%$ of the total respondents used buckets for irrigation. Because farmers who have no direct access to tertiary furrows used plastic buckets to irrigate their crops. Also, the higher number of farmers using buckets for irrigation in upstream was due to unregistered farmers who rented the farmlands. Interestingly, unknown quantity of water was abstracted per day and water user committee has never dealt with those farmers who illegally abstract water from the furrow.

Finally, the above observed problems both on furrow and bucket methods of irrigation in the study area causes the imbalances between water demand and supply in the project area. Hence, there is the conflict of interest on water allocation and sharing between farmers and this cause reduction of crop production in the study area. Therefore, there is a need to solve these problems by using effective and efficient water allocation methods.

\subsection{Scenario Analysis}

\subsubsection{Reference Scenario (2015 - 2040)}

Under reference scenario similar trends of the stream flow situation will be assumed to exist. In addition, hydrological condition and impacts of climate change on water resources also assumed to be constant. The result of this scenario is portrayed below for both water demand and unmet water demand for the project area. 


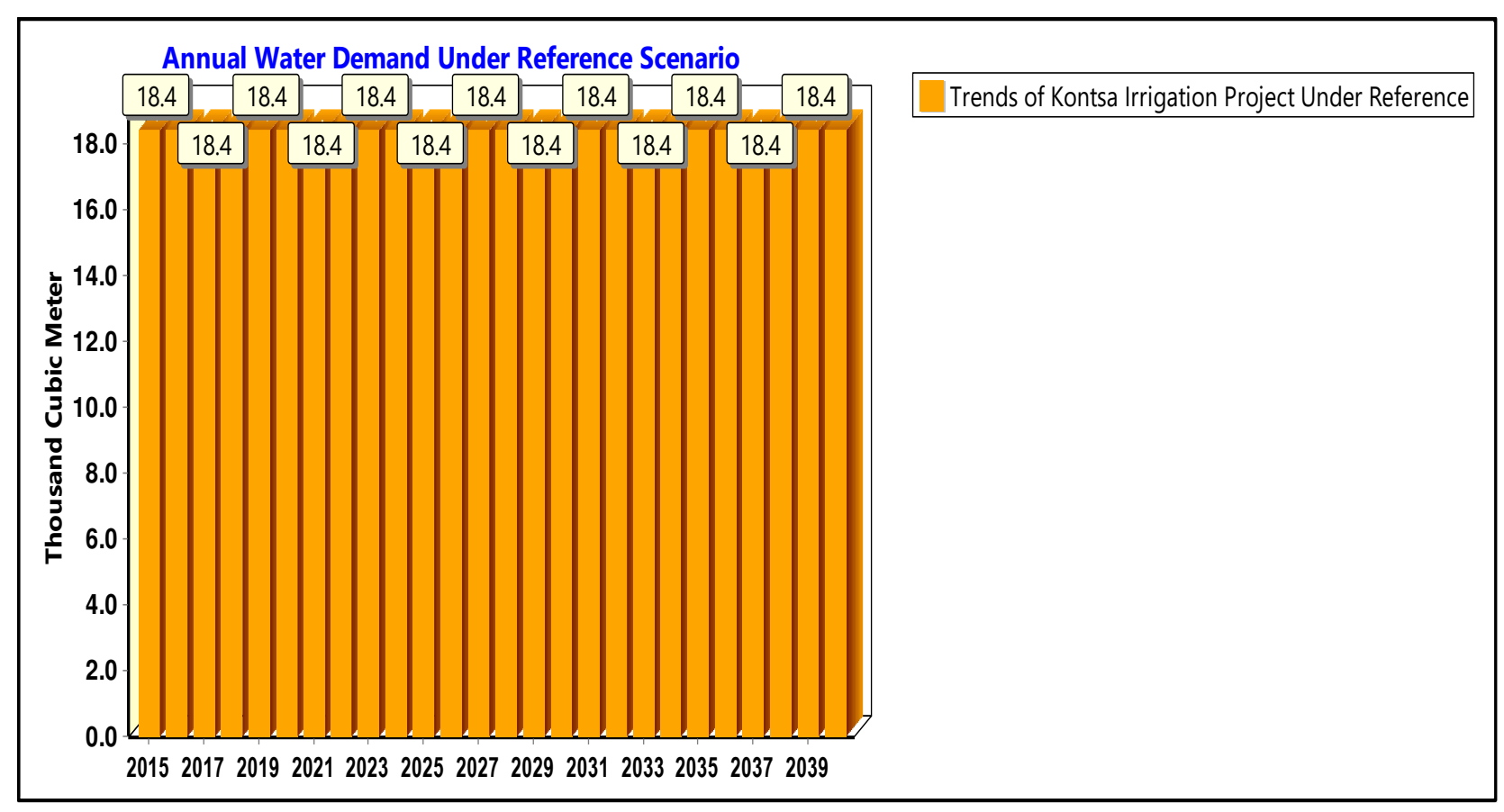

Fig. 6 Annual water demand under reference scenario

As shown in the Figure 6 irrigation water demand of the project area shows similar trend from year to year. This is because no any policy change is considered under this scenario. Hence, the amount of water needed in the base year is similar to that needed at the end of the reference scenario (2040). Accordingly, a total of $0.4784 \mathrm{MCM}$ of water is required for the demand site at the end of this scenario which is similar to the values obtained in the base year (Table 3). The result of annual unmet water demand under reference scenario for Kontsa irrigation project is shown in table 5.

Table 5 Annual unmet water demand under reference scenario

\begin{tabular}{|c|c|c|c|c|}
\hline Year & $\begin{array}{l}\text { Irrigation Water } \\
\mathrm{M}^{3} \text { ) }\end{array}$ & Demand (thousands & Year & $\begin{array}{l}\text { Irrigation Water Demand (thousands } \\
\mathrm{M}^{3} \text { ) }\end{array}$ \\
\hline 2015 & & 0 & 2028 & 0 \\
\hline 2016 & & 0 & 2029 & 0 \\
\hline 2017 & & 0 & 2030 & 0 \\
\hline 2018 & & 0 & 2031 & 0 \\
\hline 2019 & & 0 & 2032 & 0 \\
\hline
\end{tabular}



unmet water demand in this scenario. This indicates that, if all the factors which affect irrigation water demand is assumed to be constant and no policy change will be occur between the years 2015 and 2040 , the total water required for irrigation is $100 \%$ fully met.

\subsubsection{Irrigation Expansion Scenario (2021-2040)}

This scenario will bring answer to what happen to irrigation water demand between 2021 and 2040 as compared to the base year and the reference scenario if the Kontsa irrigation project is increased from 173 ha to 223 ha. The result of this scenario is depicted below in the form of graph. Figure 7 portray the result of the annual water demand for Kontsa irrigation project under irrigation expansion scenario. 


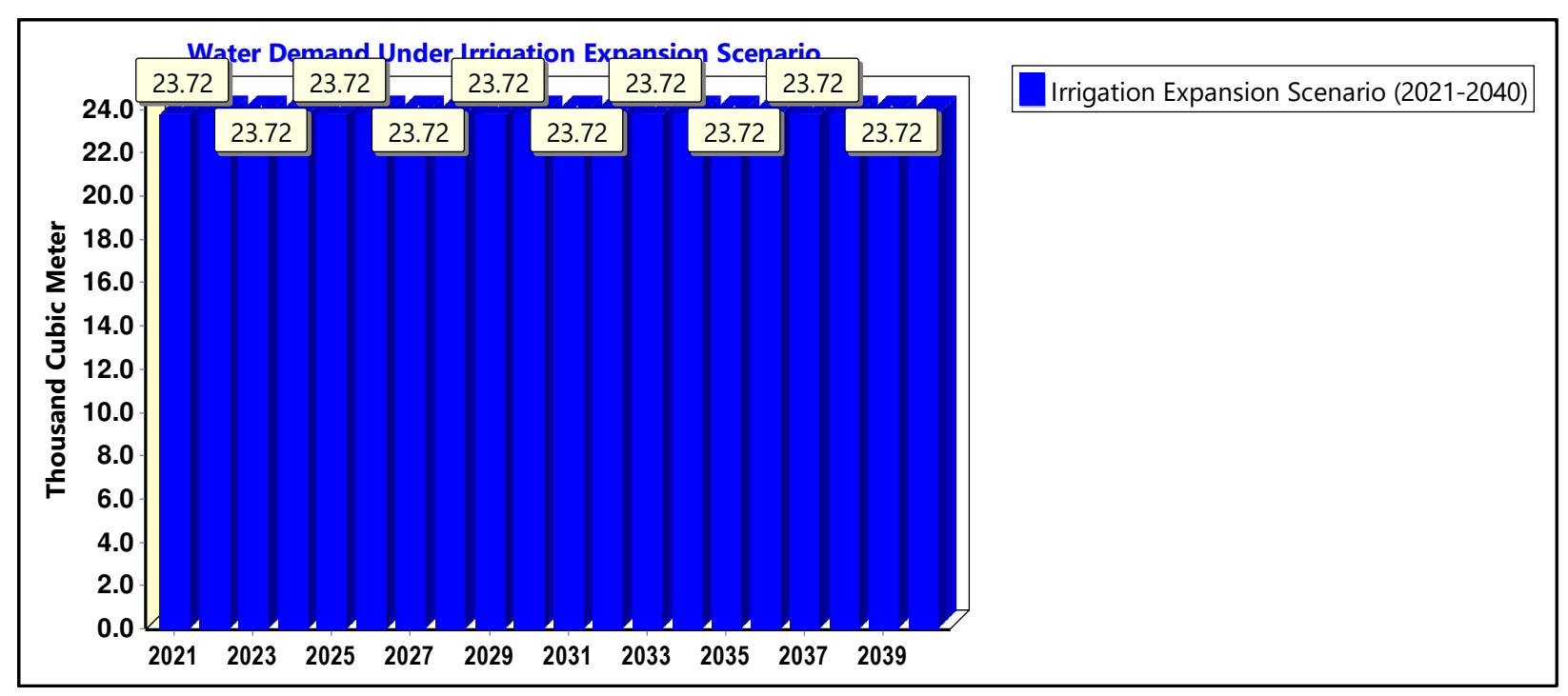

Fig. 7 Annual water demand for Kontsa irrigation project under irrigation expansion scenario

From the result of the simulation as indicated in the Figure 7 water demand for irrigation show an increment when compared to the base year and the reference scenario. Accordingly, as compared to the base year water demand for irrigation is increased from 0.0184MCM in the base year (2015) to $0.02372 \mathrm{MCM}$ at the end of irrigation expansion scenario (2040) and is also increased from $0.0184 \mathrm{MCM}$ at the end of reference scenario (2040) to $0.02372 \mathrm{MCM}$ at the end of irrigation expansion scenario7(2040). This increment in water demand is caused by the expansion of the existing irrigation project. Generally, as observed from Figure 8 a total of $0.474 \mathrm{MCM}$ water is required for irrigation in the years between 2021 and 2040 which is increased by $0.106 \mathrm{MCM}$ from the reference scenario which has an annual total irrigation water demand of $0.368 \mathrm{MCM}$ and is also increased by $0.4556 \mathrm{MCM}$ from the base year which has an annual total irrigation water demand of 0.0184MCM. Figure 8 portray the result of the annual unmet water demand for Kontsa irrigation project under irrigation expansion scenario. 


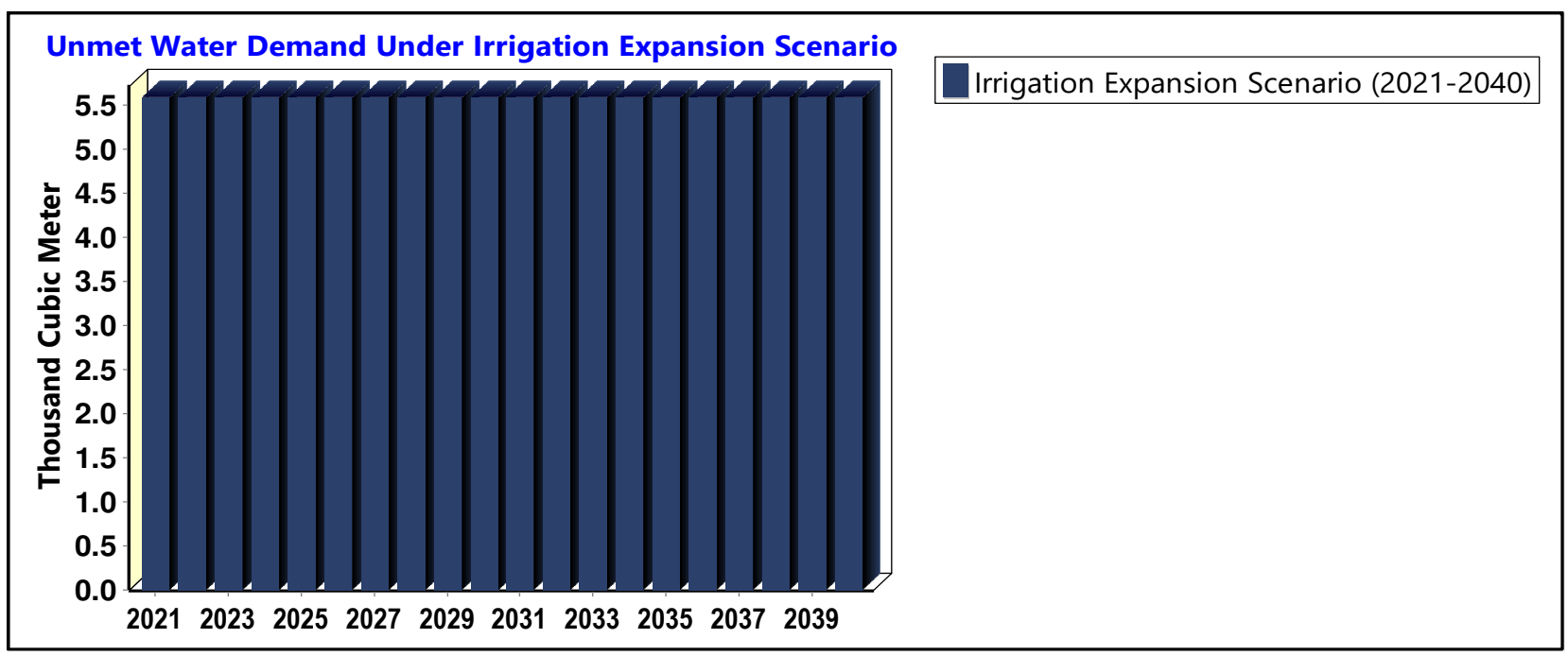

Fig. 8 Annual unmet water demand for Kontsa irrigation project under irrigation expansion scenario

As shown in the Figure 8 starting from 2021 unmet water demand for irrigation is observed. As compared to the base year and the reference scenarios of this study unmet water demand for irrigation observed in this scenario. Thus, in relation to the base year and the reference scenarios the annual total unmet water demand for irrigation is increased from OMCM in base year and in the reference scenario to $0.00558 \mathrm{MCM}$ (Figure 8) in this scenario. This is due to the expansion of the existing irrigation project in the area which cause the competition for water among farmers. Finally, a total of $0.474 \mathrm{MCM}$ of water is required and a total of $0.1116 \mathrm{MCM}$ of unmet demand will be occurred under the irrigation expansion scenarios if the factors which affect water resource is assumed to be constant as the base year.

\subsection{Proposed Strategies to Reduce Water Allocation Conflicts}

The results of this study show that, the total water resource has enough potential to fulfill current and future irrigation water demand and no unmet demand was encountered for a current account year and for future water demand if the available water resource is used properly. The result also indicates that there is scarcity of supply in irrigation expansion scenario and unmet water demand was observed. This shows that the existence of either supply delivery problem to a demand site or lack of equal distribution among farmers rather than the water availability in the project area. Due 
to this reason, there were always a conflict between farmers on water allocation and there were no water allocation strategies which were currently practiced in the study area. For this reason, the following strategies were proposed to reduce water allocation conflicts among farmers. These strategies include the formation of water users' associations, water right, water pricing, public education, as well as laws and regulations on water allocation.

\section{Conclusions}

The objective of the study was to assess the effects of practiced irrigation methods on water demand and allocation among farmers in Kontsa irrigation project for efficient and sustainable water use. Therefore, the study set the objectives of assessing the effects of selected irrigation methods on current water demand and allocation, forecast future irrigation water demand of the area by developing scenarios and propose strategies to reduce water demand and allocation conflicts among farmers in the project area. The Water evaluation and planning (WEAP) model was successfully used to assess the water demand and unmet water demand of the project area. Accordingly, the result showed that the project area has a total water demand of $0.0184 \mathrm{MCM}$ and there was no unmet water demand for the base year. The study also established that furrow irrigation was the main irrigation techniques employed by farmers followed by plastic buckets irrigation. The study also concluded that, the selected irrigation methods causes greater water losses and water shortage among farmers which result in the imbalances between water demand and supply in the project area. Hence, there is the conflict of interest on water allocation and sharing between farmers and this cause reduction of crop production in the study area.

In addition, water demand scenarios were created to forecast the future trend of water demand in the project area. For future water demand, the result indicated that there is an increment of water demand and unmet water demand from year to year. Accordingly, the result showed that an increment of water demand from $0.368 \mathrm{MCM}$ at the end of the reference scenario to $0.474 \mathrm{MCM}$ at the end of the irrigation expansion scenario. The result also indicated that an increment of unmet 
water demand from $0 \mathrm{MCM}$ at the end of the reference scenario to $0.1116 \mathrm{MCM}$ at the end of the irrigation expansion scenario if the likely future development scenarios will be fully implemented according to the plan. This occurrence of unmet water demand was due to either the existence of supply delivery problem to a demand site or lack of equal distribution among farmers. Finally, this study proposed different water allocation strategies such as the formation of water users' associations, water pricing, public education, and regulation on water allocation among farmers and other users in order to reduce water allocation conflicts among farmers.

\section{Declarations}

Ethical Approval: This article does not contain any studies with human participants or animals performed by any of the authors.

Consent to Participate: Not applicable.

Consent for Publication: Not applicable.

Competing Interests: The authors declare that they have no competing interest.

\section{References}

Ethiopia Sustainable Development and poverty Reduction Program, Ministry of Finance and Economic Development (MoFED, 2002), Addis Ababa, Ethiopia.

Hamdy A (2005) Water use Efficiency in Irrigated Agriculture: An Analytical Review. Presented at the A paper presented at the 4th WASAMED Workshop, 1-4 October, Amman, Jordan: University of Jordan.

Hope RA, Gowing JW, Jewitt GPW (2008) The contested future of irrigation in African rural livelihoods: Analysis from a water scarce catchment in South Africa. Water Policy, 10(2), $173-192$.

Hussain I, Hussain Z, Sial MH (2011) Water balance, supply and demand and irrigation efficiency of Indus basin. Pakistan Economic and Social Review, 49(1), 13-38. 
Ministry of Water Resource Development, Environment and social management framework and resettlement policy framework (MoWRD, 2008). Final Report.

Moriasi PJG, Arnold DNW, Gassman KC, Abbaspour MJ, White R, Srinivasan C, Santhi RD, Harmel A, van Griensven MW, Van Liew N, Kannan MK, Jha (2012) Swat: Model Use, Calibration, and Validation. Transactions of the ASABE, 55(4) 1491-1508, American Soc. of Agr. and Bio.l Eng.ISSN 2151-0032

Reuben N (2007) Application of the WEAP Model in Integrated Water Resources Management of the Nyando River Basin, Kenya. Jomo Kenyatta University.

WWAP (2012) The United Nations World Water Development Report 4: Managing Water under Uncertainty and Risk. (Executive Summary) (p. 68). Paris, France: United Nations Educational, Scientific and Cultural Organization.

SEI (Stockholm Environment Institute) (2011) WEAP (Water Evaluation and Planning System): Guideline and Tutorial of WEAP model.

SEI (Stockholm Environment Institute) (2012) WEAP (Water Evaluation and Planning System): Guideline and Tutorial of WEAP model.

Stockholm Environment Institute (SEI) (1999). WEAP: water evaluation and planning system. Tellus Institute, Boston

Stockholm Environmental Institute SEI, (2015). WEAP User Guide, Studies.

Yates D, Sieber J, Purkey D, Huberlee A (2005) WEAP21 - A Demand, Priority, and PreferenceDriven Water Planning Model. International Water Resources Association, Water International, Volume 30, Number 4, Pages 487-500. 